\title{
The Therapeutic Relevance of Vitamin E
}

\author{
LUCRETIA ANGHEL, LILIANA BAROIU*, ADRIAN BEZNEA, GABI TOPOR, CAMELIA ANA GRIGORE* \\ Dunarea de J os University of Galati, Medicine and Pharmacy Faculty, Department of Internal Medicine, 47 Domneasca Str., \\ 800008, Galati, Romania
}

\begin{abstract}
Maintaining cellular homeostasis in the context of its normal metabolic function is achieved by establishing the balance between its own antioxidant capacity and the level of harmful compounds resulting from the mitochondrial activity and the immune system. One of the antioxidants involved in this process is vitamin $E$ with its mostactive form - alpha-tocopherol, which exerts its functions through vitamin C. The main functions of this antioxidant are: regulation of platelet aggregation, cellular signaling, antioxidation. The therapeutic relevance of vitamin E has increased due to the incrimination of oxidative stress as a link in the pathophysiology of many chronic diseases. Respectively, the role most targeted is that of antioxidant.
\end{abstract}

Keywords: Vitamin E, antioxidants, therapy, oxidative stress

Vitamin E was discovered in 1922 by Evans and Bishop, and first synthesized in 1938. It is a collective name given to all stereoisomers tocopherols and tocotrienols. Of all forms of alpha-, beta-, gamma-, delta-, tocopherol and tocotrienols, the most active and preferred by the human body is al pha-tocopherol. Although all these molecules are peroxyl radical scavengers. It is found in considerable quantities in vegetable oils, seeds, nuts, soybeans, wheat germs, which is why vitamin E deficiency in healthy people is rarely encountered. It can occur more frequently in smokers, the elderly, and in people with some pathologies of the gastrointestinal tract, which shows that the deficiency is most often due to the disorder of absorption. The medical interest for vitamin $\mathrm{E}$ is given by the antioxidant and anti-inflammatory properties (for all its forms) [1], which in diseases such as senile macular degeneration [2], cardiovascular disease, Alzheimer's dementia, cancer, could play at least a role of protective factor.

\section{Functions of Vitamin $\mathrm{E}$}

The reactive oxygen species (ROS) as well as the nitrogen species (RNS) are formed following normal cellular functioning. ROS results from oxidative phosphorylation that occurs in the mitochondria and consists of peroxides, superoxides, hydroxyl radicals, and singular oxygen. RNSs arise from the activity of immune cells such as macrophages, which produce nitrogen oxide that reacts with superoxides to form peroxynitrite, a product that damages the cell membrane, proteins and DNA. But the cellular balance is restored due to the presence of antioxidant enzymes: catalases, lactoperoxidase, superoxide dismutases, glutathione peroxidoxin, and also some antioxidantmolecules: vitamin C, E, uric acid, bilirubin, glutathione, the latter being synthesized in concordance with other antioxidants. In case of failure of endogenous redox systems, the level of glutathione decreases and determines the occurrence of oxidative stress.

The antioxidant function of vitamin $\mathrm{E}$ is due to the fact that it reacts with the lipid peroxidic radicals resulting from the peroxidation of unsaturated fatty acids, forming the tocopherol radical, which is almost non-reactive and is reduced by ascorbic acid back to tocopherol. Therefore, this function contributes to maintaining membrane fluidity [3].

$$
\mathrm{ROO}+\text { + Vit E-OH } \rightarrow \mathrm{ROOH}+\text { VitE-O• }
$$

The regulation of platelet aggregation is accomplished by a complex mechanism that involves the promotion of prostacyclin release by alpha-tocopherol from endothelial cells. Prostacycline is a potent vasodilator and an inhibitor of platelet aggregation. Some studies suggest that tocopherols would inhibit platelet aggregation via nitric oxide and inhibition of protein kinase C $[4,5]$. In the case of overdose, respectively, the risk of bleeding increases.

Cellular signaling or vitamin $E$ as an anti-cytokine agent Alpha-tocopherol inhibits the alpha isoform of protein kinase C (PKC), and type $2 \mathrm{~A}$ protein phosphatase maintains reduced activity, preventing autophosphorylation. PKC is involved in the transcription and activation of proteins involved in the inflammatory process through the formation of 02 - - by NADPH oxidase, the production of Interleukin - $1 \beta$, and the regulation of cyclooxygenase (COX) expression [6].

\section{Co-administration with other antioxidants}

Vitamin E deficiency is a very common phenomenon in poorly developed countries, where as a causal factor of alpha-tocopherol depletion, malnutrition occurs, and supplementation leading to reversal of deficiency symptoms: hyporeflexia, ataxia, dysdiadocokinesis, digital agnosis [7]. These manifestations can also be identified in patients with conditions such as celiac disease, intestinal resection, cystic fibrosis, chronic cholestasis, BassenKornzweig syndrome (abetalipoproteinemia). The singular administration of alpha-tocopherol in such cases will prevent its plasma depletion. However, the single use of vitamin $\mathrm{E}$ in order to reduce the risk of developing cardiovascular disease, for example, is not sufficient.

Ascorbic acid. One study showed that the combination with ascorbic acid in long-term supplementation of alphatocopherol reduced the level of lipid peroxidation in vivo and in vitro, which would nothave been possible by single administration of ascorbic acid or alpha-tocopherol [8].

The recommended dose of vitamin $\mathrm{C}$ for adults is $90 \mathrm{mg}$ / day (men), and $75 \mathrm{mg} /$ day (women). The maximum tolerable dose is $2 \mathrm{~g} /$ day, when overcoming gastrointestinal disorders. Exceeding the usual doses may: have prooxidative effects, increase renal excretion of uric acid and oxalates favoring the emergence of renal lithiasis, contribute to depletion of vitamin B12 reserves and iron overload [9].

\footnotetext{
* email: lilibaroiu@yahoo.com; cameliaanagrigore@yahoo.com
} 
Vitamin E supplementation in people with type 2 diabetes succeeds in improving glycemic control, diminishing insulin resistance and altering endothelial function. And the association with ascorbic acid is quite promising in combating complications according to metaanalyzes of randomized trials [10-12].

At the basis of constituting Alzheimer's disease according to the hypothesis of beta-amyloid toxicity is lipid and protein oxidation through free radicals. Theoretically, the administration of antioxidants such as vitamin $E$ in combination with vitamin $\mathrm{C}$ would slow down this process. However, the data obtained by some studies in this regard are contradictory: while in some participants there was a cognitive improvement ranging from small to insignificant, in others there was no positive effect at all [13-16].

Selenium. It plays a significant role in combating oxidative stress, being a component of glutathione peroxidase. It also regulates the redox status of ascorbic acid. The recommended dose for administration is $55 \mu \mathrm{g}$, for both women and men. The maximum tolerable dose is $400 \mu \mathrm{g}$. In the case of exceeding daily or maximum tolerable doses, two conditions are distinguished: acute intoxication and chronic selenosis, usually marked by gastrointestinal and neurological disorders $[9,17]$.

Although the SELECT trial [18] suggested that the administration of $400 \mathrm{IU} /$ day (the maximum tolerated dose being $1000 \mathrm{mg}$ and the recommended dose - 15mg / day) of alpha-tocopherol increased the risk of prostate cancer, it is obvious that no consideration has been given the pro-oxidative effect of alpha-tocopherol that increases directly proportional to the dose, while also the depletion of gamma-tocopherol that has protective effect in this type of cancer [19], and that already at a dose of 150 IU / day increases the risk of mortality for whatever reason [20]. It should be mentioned that in people who were given 400 $\mathrm{IU} /$ day tocopherol and $200 \mu \mathrm{g} /$ day selenium, there was a low risk of cancer. This can be explained by the involvement of selenium in the fight against oxidative stress, particularly through selenoprotein $\mathrm{P}$ that would protectendothelial cells against (RNS), such as peroxynitrite. In the case of coadministration of selenium and alpha-tocopherol respectively, partial protection against ROS and RNS is achieved at the cellular level. Therefore oxidative stress can be one of the causal factors of the oncological pathology and in the case of the disease already established to become a protective one.

Zinc and $\beta$-Carotene. In senile macular degeneration it has been shown to have a beneficial effect of alphatocopherol at doses of $>22.4 \mathrm{IU} /$ day compared to lower doses [21,22]. Although two other randomized trials failed to highlight the protective effect of vitamin E in DMS, subjects were administered $500 \mathrm{IU} /$ day d-alpha-tocopherol [23], and $111 \mathrm{IU}$ dl-alpha-tocopherol associated with 20 $\mathrm{mg} /$ day $\beta$-carotene [24]. Age-Related Eye Disease Study (AREDS) showed a $25 \%$ reduction in the risk of advancing DMS in subjects taking the following daily formula: 400 IU dl-alpha-tocopheryl acetate, beta-carotene $15 \mathrm{mg}$, vitamin C $500 \mathrm{mg}$, zinc $80 \mathrm{mg}$, copper $2 \mathrm{mg}$, compared to the placebo group [25]. And a follow-up epidemiological study associated the decrease of the mortality mainly due to cardiac cause to the participants who received zinc [2].

\section{Conclusions}

The existence of diversity and inconsistency of results obtained from numerous studies targeting the therapeutic utility of vitamin $\mathrm{E}$ in chronic pathologies is due to several variables. The methods used, mechanisms not yet elucidated of some pathologies, the particularities of the subgroups of subjects concerned, the limits given by the exogenous and endogenous factors, mainly describe these variables. However, the current literature inspires the view that the benefit of using vitamin $E$ predominates over the adverse outcomes or adverse effects.

Interpretation of the lack of benefit of administering alpha-tocopherol in cancer should be made in the pathological context, starting from the hypothesis that chronic inflammation, as well as damage to cellular structures (in particular, the genetic apparatus - DNA) beyond the repair limit by means of ROS and RNS, is an important cause in triggering uncontrolled proliferation of tumor cells. But at the same time, due to oxidative stress, the tumor suppressor genes that remain functional in some of the tumor cells can be activated. In this case, the reduction of ROS and RNS by the administration of antioxidants is not a rational one.

Vitamin E with some of its stereoisomers - tocopherols and tocotrienols, may serve as a participant in regulating oxidation status at the cellular level. But this mechanism of regulation also includes other antioxidants, which implies a complexity of interpreting the benefit of administration in chronic pathologies.

The administration of maximum tolerable doses of longlasting vitamin $\mathrm{E}$ cannot be argued.

An in-depth study of the pathophysiological mechanisms in: cardiovascular disease, Alzheimer's dementia, senile macular degeneration, diabetes, cancer is needed to reassess the role of antioxidants and their potential to contribute to maintaining homeostasis.

\section{References}

1.NAZRUN AS et al. The anti-inflammatory role of vitamin e in prevention of osteoporosis. In Adv Pharmacol Sci. 2012;2012:142702. 2.CHEW EMILY Y. et al. Long-TermEffects of Vitamins $C$ and $E$, âCarotene, and Zinc on Age-related Macular Degeneration. In Ophthalmology, Volume 120, Issue 8, 1604 - 1611.e4.

3.HOWARD AC, MCNEIL AK, MCNEIL PL. Promotion of plasma membrane repair by vitamin E. In Nat Commun. 2011;2:597.

4.SALDEEN T, LI D, MEHTA J L. Differential effects of alpha- and gammatocopherol on low-density lipoprotein oxidation, superoxide activity, platelet aggregation and arterial thrombogenesis. In J Am Coll Cardiol 1999;34:1208-15.

5.FREEDMAN JE ET AL. Impaired platelet production of nitric oxide predicts presence of acute coronary syndromes. In Circulation 1998;98:1481-6.

6.RICCIARELLI R et al. alpha-Tocopherol specifically inactivates cellular protein kinase $\mathrm{C}$ alpha by changing its phosphorylation state. In Biochem J. 1998;334 ( Pt 1)(Pt 1):243-249.

7.KALRA V et al. Vitamin E deficiency and associate and neurological deficits in children with protein-energy malnutrition. In J Trop Pediatr 1998:44:291-5.

8.ELINA PORKKALA-SARATAHO et al. Long-Term Effects of Vitamin E, Vitamin C, and Combined Supplementation on Urinary 7-Hydro-8Oxo-22 -Deoxyguanosine, Serum Cholesterol Oxidation Products, and Oxidation Resistance of Lipids in Nondepleted Men. In Arterioscler ThrombVasc Biol. 2000 Sep;20(9):2087-93.

9. *** FOOD AND NUTRITION BOARD. Institute of Medicine. Dietary Reference Intakes for vitamin C, vitamin E, selenium, and carotenoids. Washington: National Academies Press; 2000.

10.MONTERO D et al. Effect of antioxidant vitamin supplementation on endothelial function in type 2 diabetes mellitus: a systematic review and meta-analysis of randomized controlledtrials. In Obes Rev. 2014;15(2):107-16.

11.GEORGE PS, PEARSON ER, WITHAM MD. Effect of vitamin D supplementation on glycaemic control and insulin resistance: a systematic review and meta-analysis. In Diabet Med. 2012;29(8):e14250. 
12.XU R et al. Influence of vitamin E supplementation on glycaemic control: a meta-analysis of randomised controlled trials. In PLOS ONE. 2014;9(4):e95008.

13.GRODSTEIN F, CHEN J, WILLETT WC. High-dose antioxidant supplements and cognitive function in community-dwelling elderly women. In Am J Clin Nutr. 2003;77:975-84.

14.ZANDI PP et al. Reduce drisk of Alzheimer disease in users of antioxidant vitamin supplements: the Cache County Study. In Arch Neurol. 2004;61:82-8.

15.LAURIN D et al. Midlife dietary intake of antioxidants and risk of late-life incident dementia: the Honolulu-Asia AgingStudy. In Am J Epidemiol. 2004;159:959-67.

16.GRAY SL et al. Antioxidant vitamin supplement use and risk of dementia or Alzheimer's disease in older adults. In J Am Geriatr Soc. 2008;56:291-5.

17.*** National Research Council (US) Subcommittee on Selenium. Selenium in Nutrition: Revised Edition. Washington (DC): National Academies Press (US); 1983. 7, Effects of Excess Selenium. Available from: https://www.ncbi.nlm.nih.gov/books/NBK216723/

18.KLEIN EA et al. Vitamin E and the Risk of Prostate Cancer: The Selenium and Vitamin E Cancer Prevention Trial (SELECT). In JAMA 2011;306(14):1549-1556.
19.QING JIANG et al. ã-Tocopherol, the major form of vitamin E in the US diet, deserves more attention. In The American J ournal of Clinical Nutrition, Volume 74, Issue 6, December 2001, P.714-722.

20.MILLER E.R., $3^{\text {rd }}$ et al. Meta-analysis: high-dosage vitamin E supplementation may increase all-cause mortality. In Ann Intern Med 2005;142:37-46

21.CHONG EW-T et al. Dietary antioxidants and primary prevention of age-related macular degeneration: systematic review and metaanalysis. In BMJ 2007;335:755.

22.EVANS ]. Primary prevention of age related macular degeneration. In BMJ 2007;335:729.

23.TAYLOR HR et al. Vitamin E supplementation and macular degeneration: randomized controlled trial. In BMJ 2002;325:11.

24.TEIKARI J M etal. Long-term supplementation with alpha-tocopherol and beta-carotene and age-related cataract. In Acta Ophthalmol Scand 1997;75:634-40.

25.*** Age-Related Eye Disease Study Research Group. A randomized, placebo-controlled, clinical trial of high-dose supplementation with vitamins $C$ and $E$, beta carotene, and zinc for age-related macular degeneration and vision loss: AREDS report no. 8. In Arch Ophthalmol 2001;119:1417-36.

$\overline{\text { Manuscript received: } 28.08 .2019}$ 